\title{
El archivo de la Compañía Industrial de Atlixco S. A. (CIASA): su función y organización documental
}

The Archive of the Compañía Industrial de Atlixco S. A. (CIASA): its Purpose and Documentary Organization

\author{
Mariano Castellanos Arenas \\ Departamento de Investigaciones Históricas del Movimiento Obrero \\ Benemérita Universidad Autónoma de Puebla \\ castellanos.arenas@gmail.com
}

Recibido: 6 de abril de 2018 - Aprobado: 22 de mayo de 2018

Cómo citar este artículo: Mariano Castellanos Arenas, "El archivo de la Compañía Industrial de Atlixco S. A. (CIASA): su función y organización documental", en Legajos. Boletín del Archivo General de la Nación, núm. 17 (septiembre-diciembre 2018), pp. 86-119.

\section{Resumen}

Los archivos históricos de empresa son parte del patrimonio industrial que el desarrollo de la mecanización nos legó. En estos archivos se guarda la memoria económica, política y social de toda una sociedad. Sus documentos son una importante fuente de información cuantitativa, y sobre todo cualitativa, que difícilmente podemos encontrar en fondos públicos y con la que se pueden construir importantes procesos históricos. En este sentido el trabajo titulado "El archivo de la Compañía Industrial de Atlixco S. A. (CIASA): su función y organización documental", trata sobre los mecanismos de generación de información durante los años de actividad de esta empresa y su fábrica textil (1899-1967). Asimismo, aborda la conversión a fondo documental histórico, y cómo fue organizado y puesto en valor como fuente para la investigación.

Palabras clave: archivo, función, organización, patrimonio, historia

\section{Abstract}

The historical archives of a company are part of the industrial heritage that the development of mechanization bequeathed us. In these archive the economic, political, and social memory of an entire society is kept, and its documents are an important source of quantitative and most of all qualitative information, which we can hardly find in public sources and with which important historical processes can be reconstructed. In this sense this article "El Archivo de la Compañía Industrial de Atlixco S. A. (CIASA): su función y organización documental" deals with the mechanisms regarding the information generated during this company and its textile factory's activity (1899. 1967). At the same time, it describes the transition of this company archive to a historical documentary collection, how it was organized, and how it was put into value as a source for public consultation and academic research.

Keywords: archive, function, organization, heritage, history 


\section{Introducción}

El patrimonio industrial, según el International Committee for the Conservation of the Industrial Heritage (Comité Internacional para la Conservación del Patrimonio Industrial) está compuesto:

...por los restos de la industrialización que poseen valor histórico, tecnológico, social, arquitectónico o científico. Estos restos consisten en edificios y maquinaria, talleres, molinos y fábricas, minas y sitios para procesar y refinar, almacenes y depósitos, lugares donde se genera, se transmite y se usa energía, medios de transporte y toda su infraestructura, así como los sitios donde se desarrollan las actividades sociales relacionadas con la industria, tales como la vivienda, el culto religioso o la educación. ${ }^{1}$

Pero no solo está compuesto por bienes inmuebles, sino también por infinidad de objetos, bienes muebles relacionados con la producción y/o servicio, según la vocación de cada empresa, así como por sus archivos.

El interés por los archivos de empresa y su conservación se inició a finales del siglo XIX en los países más industrializados como Francia, Alemania, Inglaterra y Estados Unidos. Muchas empresas europeas y estadounidenses como Krupp, Bayer, Lufthansa, Renault, Telcom, London Bank, Grupo Santander, Hullera Vasco-Leonesa, Coca Cola, Kodak, Sears o Ford, se dieron a la tarea de poner en valor sus archivos con el objetivo de resguardar su memoria, y han abierto al público sus fondos documentales para ser estudiados. También, universidades y centros de investigación como la European Business History Association

1 "The International Committee for the Conservation of the Industrial Heritage, TICCIH, Congress, 1973", Published by the lronbridge Gorge Museum Trust, Church Hill, Ironbridge, Telford, Shropshire, England, 1975; http://works.bepress.com/ theinternationalcommitteefortheconservationoftheindustrialheritage/11/ 
y la Harvard Business School, comenzaron a consultar los archivos de empresa para alentar una cultura empresarial a través de su estudio. ${ }^{2}$

En México surgió el interés por la investigación económica y empresarial hace unos cuarenta años, lo que contribuyó al rescate de acervos documentales. De la misma manera se crearon centros de investigación que estudian archivos como los de Pemex, Banamex, Minera Real del Monte, Fundidora de Monterrey o la Compañía Industrial de Atlixco S. A., así como de la Universidad Autónoma de Nuevo León, la Asociación Iberoamericana de Historia Empresarial, la Asociación de Archivos Privados o el Departamento de Investigaciones Históricas del Movimiento Obrero (DIHMO), por mencionar algunos ejemplos. Están trabajando en la investigación, recuperación y conservación de archivos empresariales, familiares y/o sindicales. ${ }^{3}$

El Dinmo de la Benemérita Universidad Autónoma de Puebla (BUAP) resguarda, en el Archivo Histórico del Museo Industrial de Metepec (AHMIM), los documentos de la extinta Compañía Industrial de Atlixco, S. A. (CIASA). Éste es uno de los pocos archivos en el país que conserva fondos relacionados con el mundo del trabajo. Hay que decir que no todas las empresas de este tipo guardaron sus archivos. Por ejemplo, los documentos de la fábrica La Constancia Mexicana (1934), la primera en Latinoamérica, localizada en Puebla, terminaron en el río (Atoyac) con el argumento de no tener más espacio para contenerlos; pero no así los de la Compañía Industrial Veracruzana S. A. o la Compañía Industrial de Orizaba S. A., solo por mencionar algunos de la industrial textil de los siglos XIX y XX.

El fondo documental CIASA es el único de la industria textil de Puebla que se conserva casi en su totalidad: cien metros lineales, aproximadamente, de documentos. En él podemos encontrar una fuente sumamente rica y poco explorada para la investigación histórica. Sus documentos son testimonios de los trabajadores: hombres y mujeres, niños y niñas, que no tuvieron voz propia para dejar

2 Castellanos Arenas, "Legislar para conservar", p. 162.

${ }^{3}$ Castellanos Arenas, "Legislar para conservar", p. 163. 
memoria de sí mismos. Sus recuerdos están en los documentos que hablan de los espacios en que trabajaron y los productos que con su esfuerzo generaron toda una cultura, una cultura obrera. También hay documentos que testimonian la trayectoria de la empresa y de la fábrica misma, la suerte de sus principales accionistas y empleados.

Cabe destacar, que no tememos evidencias de la fecha en que este fondo arribó al Museo Industrial de Metepec. Lo que sí se sabe es que el antropólogo Samuel Malpica Uribe (1955-2013), investigador del Centro de Investigaciones Históricas del Movimiento Obrero de la UAP, en su estudio sobre el sindicalismo en la región de Puebla consultó el archivo de la Confederación Regional Obrera Mexicana (CROM) en Atlixco, en el periodo del líder Antonio J. Hernández. Descubrió que ahí se hallaban los documentos de la empresa, y en la década de 1990 el maestro Malpica logró convencer a los dirigentes cromistas para que donaran el acervo al museo. Y finalmente fue trasladado a su lugar de origen, es decir, a la propia exfábrica de Metepec.

A partir de ese momento se creó nueva área en el museo, el Archivo Histórico, que por cierto no solo resguarda este archivo de empresa sino, también, con la misma metodología de gestión, se han rescatado, organizado y catalogado otros siete fondos, todos relacionados con el mundo del trabajo; éstos son:

- Fondo Luis $\mathcal{N}$. Morones, de quien fue un personaje importante para la historia de México, líder sindical cercano al gobierno de la República mexicana en las décadas de 1920 y 1930. Este acervo está formado por documentos personales y otros de carácter sindical.

- Fondo sindicatos de Puebla, que contiene una colección de documentos de la Junta de Conciliación y Arbitraje que tratan de problemas laborales de una gran variedad de gremios de trabajadores.

- Fondo CROM Atlixco, en formato de microfilm, contiene una importante colección de documentos relacionados con la actividad política del sindicato. 
- Fondo familia Matienzo, en formato de microfilm. Esta familia administró la importante hacienda y molino de trigo de San Mateo, propiedad de la familia Maurer de Atlixco.

- Fondo colección fotográfica MIM; casi todas las imágenes de esta colección están relacionadas con la vida industrial, principalmente con la fábrica de Metepec, con el territorio de Atlixco y con los movimientos sindicales en la región, entre otros temas.

- Fondo Miguel Ángel Peral, de dicho periodista y cronista poblano. Acervo que cuenta con manuscritos de sus libros algunos editados y otros inéditos. En 2008, al conocer el trabajo de inventario que realizábamos en el Aнмiм, la familia Peral donó sus documentos para este propósito.

- Fondo Samuel Malpica Uribe, con documentos de quien fue fundador del miм y coordinador del DiHмo. El fondo fue recientemente organizado y en él se hallan documentos personales, académicos y de su periodo como rector, también documentos de movimientos sociales y una serie importante de ensayos sobre el movimiento obrero, de gran cantidad de investigadores del tema, muchos de ellos inéditos.

Ahora bien, el fondo documental ciAsa en su papel de protagonista, nos permite comprender el contexto histórico y la constitución de un importante acervo archivístico, la composición interna de sus secciones y la relación entre sus series de expedientes. Es importante aclarar que el objetivo central de este trabajo no es crear una guía específica para este fondo, sino el de contribuir al entendimiento del funcionamiento y la organicidad de la empresa y considerar a sus expedientes, no de un modo simplemente utilitarista, sino como un todo, un bien del patrimonio que el desarrollo del pasado industrial nos ha legado.

También es importante decir que en los fondos como éste tenemos una fuente sumamente rica y poco explorada para la investigación histórica, ya que son, además, un recurso inagotable para la historia 
económica, científica, tecnológica, social y política de nuestro país. Representan una parte importante de la memoria de toda una comunidad y constituyen anclajes para la valoración de otros bienes culturales (los industriales). Sin duda son instrumentos que nos permiten explicar el pasado y testimoniar la autenticidad de todo un patrimonio, lo que a su vez pone de manifiesto la relevancia de otros fondos documentales vinculados con éstos.

Resulta fundamental subrayar que este tipo de fondos puede ser la única fuente de datos fiables y continuos para periodos en los que el gobierno no produjo estadísticas, como por ejemplo durante la Revolución mexicana, ya que son fuentes magníficas en las que podemos hallar largas series de datos ininterrumpidos. Estos documentos también nos permiten encontrar el sentido y la orientación de la trayectoria histórica de una empresa y, por lo tanto, de toda una colectividad.

Aún existen muchas limitaciones en el campo archivístico, un ejemplo es que cuando hablamos de archivos de empresas pensamos generalmente en el innegable apoyo que para la historia tienen sus documentos, para fundamentar sus resultados de modo más sólido - según suele suponerse - que con cualquier otra fuente. Una consideración más estrecha es pensar al archivo tan solo como un lugar que contiene documentos que requiere el investigador para su trabajo, tratándose por tanto de una idea que lo concibe fundamentalmente como un servicio.

En este sentido, nuestro interés es ir más allá, se trata de reflexionar sobre lo tangible de su estructura, pero también sobre los valores intangibles como archivo. Como dice Michel Foucault:

...no se trata solo de interpretar los archivos, ni tampoco determinar si son veraces o no, o cuál es su valor expresivo. Se trata de trabajarlos desde el interior y en su totalidad, en una tarea de investigación histórica que "lo organiza, lo recorta, lo distribuye, lo ordena, lo reparte en niveles, establece series, distingue lo que es perti- 
nente de lo que no lo es, fija elementos, define unidades, describe relaciones".

\section{La función interna de la cIASA y su fábrica textil de Metepec}

La CIASA se fundó en 1899 por un grupo de empresarios extranjeros y nacionales - éstos con un menor peso-, que residían en la Ciudad de México y que tenían inversiones en otras empresas. El español Luis Barroso Arias, representante y artífice de la CIASA, se asoció con otros de sus paisanos y algunos franceses para construir la factoría, cuyo objetivo era fabricar telas de algodón. Para tal efecto adquirieron la hacienda de San Diego Metepec, en Atlixco, Puebla, a fin de erigir allí las instalaciones de su ambicioso proyecto: la fábrica de hilados, tejidos y acabados de algodón Metepec. Después de más de seis décadas como la fábrica más importante de la región Puebla-Tlaxcala, tuvo que cerrar sus puertas definitivamente en $1967 .^{5}$

Es importante aclarar que en esta parte me interesa hacer una referencia al empleo de sus documentos, para entender mejor el funcionamiento interno de la CIASA, ya que sus series de expedientes

${ }^{4}$ Foucault, La arqueología del saber. p. 10.

${ }^{5}$ Barroso Arias fue el representante de la Compañía Industrial La Virgen - propietaria de la fábrica textil La Virgen, ubicada en Michoacán-, accionista de la Compañía Industrial de Orizaba, y gerente de la sociedad B. Rovés y Cía., estas dos empresas con domicilio en la Ciudad de México. Al mismo tiempo, era miembro del consejo de administración de la Compañía Industrial de San Antonio Abad, que explotaba la fábrica textil del mismo nombre, además de Barrón y La Colmena, las tres ubicadas en la capital del país; también participaba en la Negociación Agrícola de Xico. Barroso se asoció con Agustín Garcin, empresario de origen francés, del valle de Barcelonnette, quien a su vez era socio, entre otras empresas, de la Compañía Industrial Manufacturera, cuyas fábricas textiles se hallaban en Jalisco. También se asoció con el asturiano Íñigo Noriega Lasso, quien ya tenía grandes inversiones en la industria y en el comercio. Podría decirse que estos tres empresarios fueron quienes concibieron el proyecto original de la CIASA. Estos accionistas participaban también, en el consejo de administración de la Fábrica de Papel San Rafael, en cuyo 


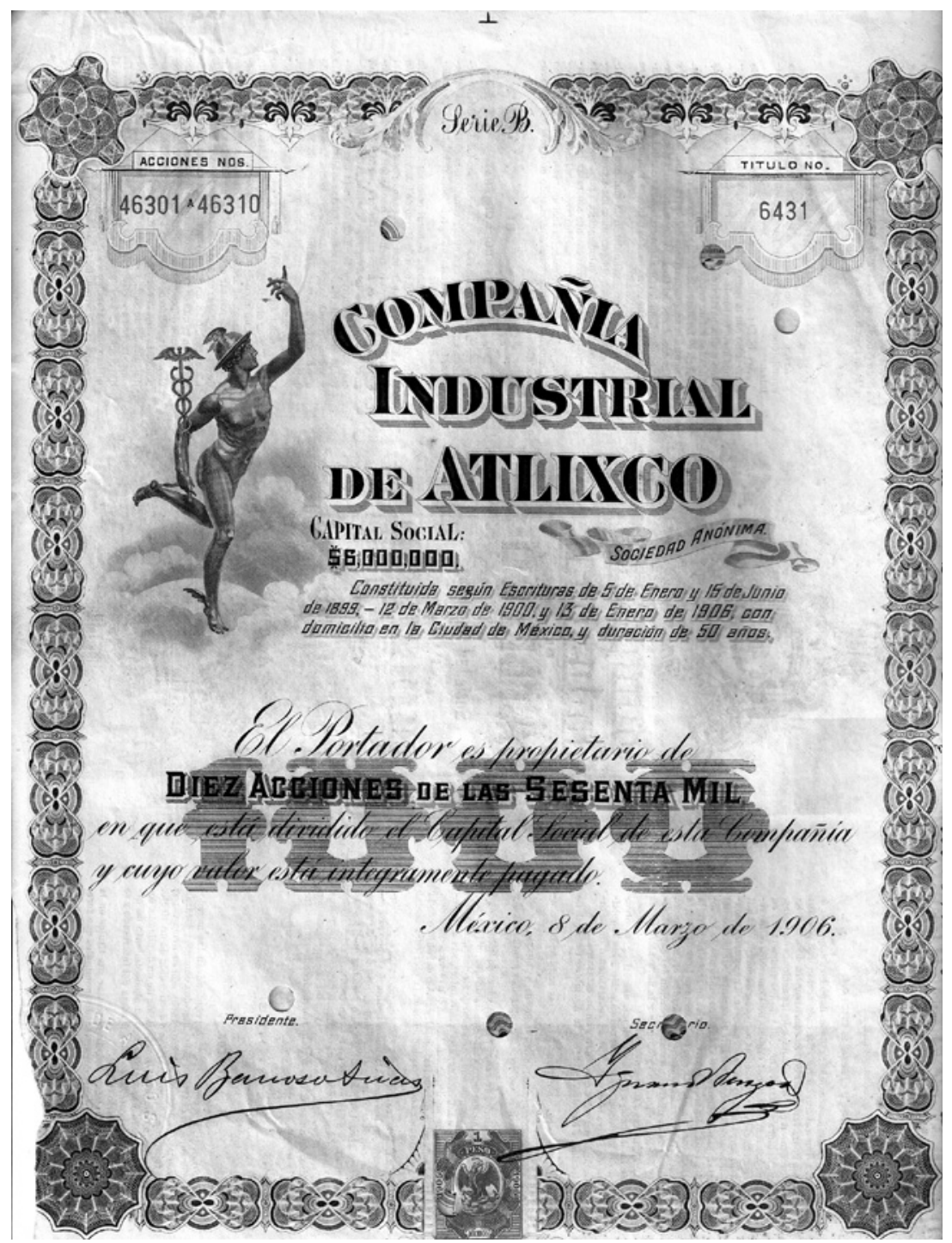

Imagen 1. Acción. Archivo Histórico del Museo Industrial de Metepec, serie acciones, 1906, exp. 1. 


\section{nos permitirán comprender la estructura de toda empresa. ${ }^{6}$ Para ello} es necesario fijar muy bien dos conceptos: el de dinero y el de capital.

beneficio y en el de la CIASA, conectaron una vía férrea que unía a las fábricas de ambas firmas con el gran mercado de la Ciudad de México, formando para ello la Compañía de Ferrocarril de San Rafael y Atlixco S.A. Estos empresarios además de ser económicamente muy importantes, se aliaron con otros sobresalientes políticos y hombres de negocios. Uno de estos fue el vasco Antonio Basagoiti, quien mantuvo - como Barroso - una estrecha relación con el presidente de la república Porfirio Díaz. La fábrica de Metepec comenzó a funcionar en 1902, llegando a producir más de sesenta artículos textiles diferentes. Gracias a las aguas de los manantiales de San Baltasar y el río Cantarranas se obtuvo una excelente calidad en el acabado de sus productos. Siempre se reconoció que sus telas eran de una calidad similar a las que se producían en Canadá, Estados Unidos e Inglaterra. Por esta razón, la fábrica se constituyó en un importante mercado para proveedores de combustible, productos químicos, refacciones, algodón nacional, americano y egipcio, principalmente. Además era la única fábrica perteneciente a una sociedad anónima, la primera en Metepec, México, también fue la única que tuvo su domicilio social en la Ciudad de México. Esta sociedad se constituyó con un capital representado por 20000 acciones de $\$ 100$ cada una; al poco tiempo se emitieron más acciones, y para 1907 contaba con 6 millones de capital gracias a la colocación de nuevas acciones en algunas bolsas de valores de Europa. Durante la revolución mexicana se comenzaron a modificar las condiciones de trabajo y para 1912 se acordó el primer "contrato-ley" de la historia de México, el cual, entre otras cosas, estableció que ningún obrero trabajaría más de ocho máquinas cardadoras y la jornada máxima de trabajo fue reducida a 10 horas. Parte importante de la historia de la empresa fue la vida sindical. El sindicato actuó como agente de disciplina y monopolizaba las actividades bancarias y de seguros, diversiones, transportes, biblioteca, sanatorio y escuela. "El sindicato no mantenía relaciones con la comunidad, sino que era la comunidad". Sin embargo, su hegemonía decayó con el curso del tiempo, y ya para abril de 1964 la Coalición Nacional de Obreros Textiles emplazó a huelga debido a que los empresarios se negaban a revisar el contrato colectivo. En julio del mismo año, la empresa y el sindicato acordaron que la CIASA cediera la fábrica como indemnización a los obreros. Entonces el sindicato formó una cooperativa, pero terminó en un rotundo fracaso, cerrando la factoría definitivamente en 1967. Véase a Castañeda, Las vertientes de los ríos; Malpica, Arqueología Industrial; Malpica, Metepec la máquina; Pacheco, Los empresarios; Gamboa, Los empresarios de ayer.

${ }^{6}$ Mediante el "lenguaje" contable se puede hacer una reconstrucción del desarrollo de la actividad económica de la CIASA, en lo que se refiere a producción y ventas. 
El dinero es un bien como cualquier otro y el de capital está representado por las acciones o títulos de la compañía. En el registro y clasificación de los elementos que forman el punto de partida en la vida de la CIASA es el balance: precisamente donde se registraba la información pormenorizada de los elementos de que disponía en el momento en que se puso en marcha; es decir, su capital. Éste expresaba el quantum de la riqueza, formada por el conjunto de capitales invertidos en bienes inmuebles y muebles (terrenos, edificios, maquinaria, materia prima y otros insumos).

En una empresa grande como la CIASA, el capital está reunido por los aportes de un número indeterminado y frecuentemente variable de personas y los conceptos de inversión e inversionistas son fundamentales para el estudio de su proceso contable. A las personas que aportan los capitales se les llama capitalistas, o más específicamente accionistas si se trata de una sociedad por acciones como esa; pero los mismos personajes también son acreedores, pues la empresa les debía el dinero que invirtieron comprando sus acciones.

Los bienes que manejaba CIASA, incluían dinero en efectivo y cuentas pendientes de cobro, inventarios, máquinas, materia prima, edificios y cantidades pagadas por servicios que formaban el activo. Las personas y empresas que le proporcionaban sus inversiones, diversos bienes y servicios, formaban el pasivo. Así, el balance estaba formado por el activo en bienes e inversiones, y el pasivo por los acreedores.

En la CIASA, en tanto empresa dedicada a la transformación, producción y distribución de mercancías, era indispensable que el dinero, las mercancías y las cuentas estuvieran ligadas en una secuencia sin fin,

Este leguaje es "el arte de registrar, clasificar y resumir de manera significativa y en términos monetarios, transacciones que son en parte, al menos, de carácter financiero, así como de interpretar los resultados obtenidos". Los libros de contabilidad se llevaban generalmente por el método de partida doble, que estaba muy difundido a finales del siglo XIX y era el que usaban todas las negociaciones de importancia. $L a$ organización de la Casa de Comercio, serie informes, Archivo Histórico del Museo Industrial de Metepec. Del Raso, Curso completo; Prieto, Principios de contabilidad. 
ya que el dinero se transformaba en mercancías y éstas en cuentas por cobrar, las cuales a su vez se convertían en dinero; iniciándose así un nuevo ciclo que se repetía indefinidamente. Como en toda empresa, el dinero, las mercancías y cuentas por cobrar formaban el activo circulante, mientras que el activo representado por terrenos, edificios, maquinaria, herramienta y equipo en general era el activo fijo, es decir, el que estaba formado por propiedades inertes pero productivas, cuyo valor en dinero no estaba en movimiento continuo sino "congelado".

En la CIASA la inversión en activo fijo era cuantiosa y su recuperación estuvo en función de los ingresos que producía el activo circulante, en este caso por la venta de mercancías. La recuperación era paulatina y se realizó durante todo el tiempo en que el activo fijo estuvo en condiciones de uso y permitió obtener ingresos por la venta de productos elaborados.

En cuanto al pasivo, resulta mucho más fácil de detectar pues se refiere siempre a los acreedores. En él se hacía una separación, agrupando en primer término a los acreedores a quienes debía pagarse dentro de un plazo relativamente corto, y que por lo general se fijaba en un año; luego venían los acreedores que representaban adeudos a un plazo mayor. Estos dos grupos formaban, respectivamente, el pasivo circulante o a corto plazo, y el pasivo fijo o a largo plazo. Un ejemplo sería la siguiente imagen (2).

Cabe destacar que el método de contabilidad que la empresa llevaba es el de partida doble. Aquí observamos que éste fue aplicado en algunos libros principales de la ciasa. Había quien recibía y quien entregaba, es decir, el primero sería el deudor y el segundo el acreedor, lo que se asentaba dos veces, "por partida doble". Por este método las mismas cantidades que se cargan se abonan, lo que da por resultado una igualdad absoluta entre la suma de todas las cantidades cargadas y la de las abonadas. A la hora que se quisiera, se podía comprobar la exactitud o inexactitud de las partidas pasadas de un libro a otro, lo que constituye una ventaja peculiar y de sumo interés de dicho método, como vemos en la imagen anterior. 


\begin{tabular}{|lr|lr|}
\hline Activo & & Pasivo & \\
\hline & 15372.34 & Capital Social & 3500000.00 \\
Caja & 5275.00 & Empréstito & 1400000.00 \\
Depósitos & 34140.75 & Acreedores diversos & 61687.00 \\
Propiedades Rusticas & 324423.91 & Cambio & 100256.01 \\
Obras Hidráulicas & 1393086.67 & Siemens \& Halske & 11797.72 \\
Edificios & 325545.79 & Wilfred Maccabe & 395.00 \\
Pueblo de Metepec & 1942183.56 & Sotero de Juambelz & 3000.00 \\
Maquinaria & 9812.70 & Adolfo Weinzorn & 3200.55 \\
Muebla, útiles y enceres. & 172195.64 & Letras a pagar & 13685.21 \\
Ferrocarril & 70300.00 & Documentos a pagar & 97715.37 \\
Instalación Eléctrica & 161392.36 & Comisión del consejo de Puebla & 7206.40 \\
Refacciones & 160295.12 & Ganancias y perdidas & 56836.77 \\
Algodones & 82334.27 & & \\
Manufacturas, sección Blanqueo y & 10342.95 & & \\
Estampe. & 68653.80 & & \\
Drogas & 349.60 & & \\
Mercancias de México & 172840.00 & & \\
Timbres especiales 5\% & 6114.73 & & \\
Obligaciones & 904.77 & & \\
Tienda de Fábrica. & 143357.69 & & \\
Combustible & & & \\
Deudores diversos & & & \\
\hline \multicolumn{2}{|c|}{ El Activo es de \$5 253 080.95 pasivo es de \$5 253 080.95 } \\
\hline
\end{tabular}

Imagen 2. Activo y pasivo de la CIASA en 1902. AHEM, serie contabilidad, libro de inventario núm. 1, inventario del 31 de diciembre de 1902, exp. 204.

En la contabilidad llevada por partida doble encontramos dos columnas: la del lado izquierdo se refiere al debe y la del lado derecho al haber. Una operación se anotaba en el haber cuando la empresa recibía, compraba o contrataba algún bien o servicio, caso en el que la cuenta era cargada. Cuando la empresa otorgaba algún bien la cuenta era abonada, y la operación se anotaba en el debe. En resumen, en el haber encontramos el pasivo de la empresa; es decir, las fuentes por medio de las cuales la compañía obtuvo sus recursos así como las ganancias producidas en el periodo y que debían pagarse en forma de dividendos o utilidades a los accionistas. Mientras en el debe hallamos el activo, esto es, los propios recursos con que contaba la empresa, como edificios, maquinaria, etcétera. ${ }^{7}$

Las transacciones comerciales de la CIASA eran muy numerosas, pero analizándolas con detenimiento se descubre que no eran tan diversas como a primera vista pareciera ser. Por el contrario, en

${ }^{7}$ Del Raso, Curso completo, p. 47. 


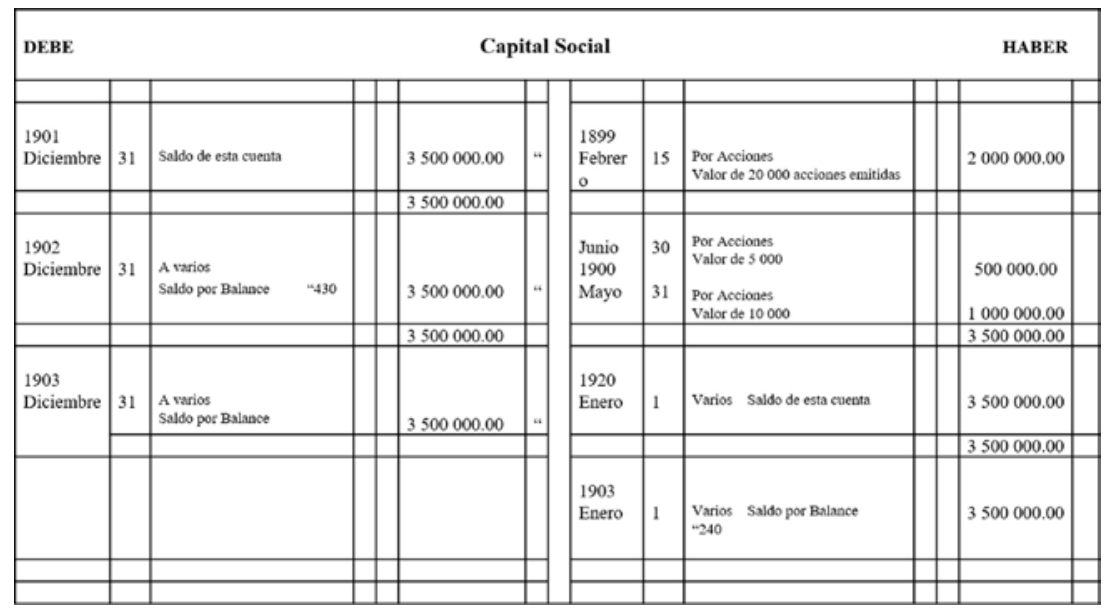

Imagen 3. Método de Partida Doble. AHEm, libro mayor, serie contabilidad, exp. 036.

la mayoría de los casos se reducían a una serie de compras, ventas, cobros y pagos que originaban productos y gastos que formaba la actividad cotidiana de la fábrica y de la empresa. Cada una de estas transacciones, de acuerdo con el enunciado de la teoría de la partida doble, afectaba dos veces el balance, más sin alterar su equilibrio. ${ }^{8}$

En cuanto a los libros principales de la contabilidad, en México el Código de Comercio en vigor - del 15 de septiembre de $1889-$ imponía a los comerciantes o empresarios, como se asienta en el artículo 33 del capítulo III, la obligación de llevar su contabilidad principalmente en tres libros: el libro diario, el libro mayor y el de inventarios. Además, las sociedades o compañías por acciones, decía

${ }^{8}$ Por ejemplo, en el caso del aumento y disminución del activo, podía presentarse al comprar mercancías, al depositar dinero en algún banco o al pagar algún servicio por adelantado por parte de la empresa. En cualquiera de estas operaciones existiría el mismo fenómeno; es decir, aumentaba el activo por la cosa comprada o el depósito hecho, y disminuía el dinero disponible por la cantidad pagada. También podía darse el aumento del activo y del pasivo. El primero siempre aumentaba por el dinero o los bienes adquiridos, y en contrapartida siempre aumentaba el segundo a favor de los acreedores o proveedores. Raso, Curso completo, p. 49. 
el mismo artículo, llevarían también libros de actas, donde constarían todos los acuerdos de las juntas o sesiones del consejo de administración. ${ }^{9}$ El código exigía, asimismo, que estos libros estuviesen encuadernados, foliados y autorizados por la oficina recaudadora de impuestos. Todas estas disposiciones provenían en su origen de las ordenanzas de Bilbao, que hasta el penúltimo tercio del siglo xix normaron las operaciones mercantiles. ${ }^{10}$

El libro mayor era el registro de contabilidad por excelencia, aunque presentaba el inconveniente, desde un punto de vista práctico, de conservar su contenido clasificado por cuentas. En cambio, no había más sitio en el que se pudiera leer íntegramente el registro de una operación que en el libro diario, del cual hablaremos más adelante. En el archivo de la CiASA ambas series están completas y en perfecto estado, abarcando de 1899 a 1967.

En los libros diario encontramos la historia de la negociación. Resulta ser el más importante porque en él se registraban una a una y en orden cronológico las cuentas. Como su nombre lo indica, era un registro de las operaciones practicadas cada día. Sus asientos eran técnicamente iguales a los de mayor, pero en aquél se agregaba una descripción completa de la operación, mencionando en ella, en algunos casos, los números y clase de documentos que la comprobaban, como recibos, facturas o contratos. ${ }^{11}$

Es cierto que tanto el mayor como el diario contenían la misma información básica, y que al registrarla en ambos libros aparentemente se duplicaba el trabajo del tenedor de libros. Pero el diario era la puerta de entrada a las operaciones en la contabilidad, las cuales se inscribían en él por segunda vez, pero ahora clasificadas por cuentas en orden cronológico. La necesidad de pasar al libro mayor los asientos del diario duplicaba, estrictamente hablando, el trabajo de contabilidad; pero esta labor podía simplificarse en gran parte, o aun supri-

\footnotetext{
${ }^{9}$ Código de Comercio de los Estados Unidos Mexicanos, p. 14.

${ }^{10}$ Del Raso, Curso completo, p. 35.

${ }^{11}$ Del Raso, Curso completo, p. 32.
} 
mirse, dependiendo del formato que se adoptara en el diario. Era las formas fundamentales del libro diario: la primera a dos columnas, al que se llamaba diario continental, y la segunda a múltiples columnas, llamado diario tabular, que es el que se usaba en la CIASA.

El trabajo de pasar los asientos del diario al mayor era especialmente laborioso, y aunque sencillo se presentaban errores y omisiones que después dificultaban la interpretación de las cuentas. Lo más conveniente era proceder con sumo cuidado al hacer esas transcripciones, y para tal efecto se acostumbraba utilizar los folios o números de página, para indicar que las cantidades ya habían sido pasadas. En otras palabras, la colocación de los folios constituía un sistema de referencias cruzadas; es decir, en las cuentas del mayor había una pequeña columna en donde se anotaba el número de la página del diario de donde se tomaba la cantidad transcrita. ${ }^{12}$

En los libros de inventario, ubicados dentro de los libros principales, se llevaba de forma detallada la existencia de los bienes, créditos y valores que formaban el activo de la ciasa. Prácticamente era una lista bienes, que constaba de un encabezado con el nombre de la negociación y la indicación de la fecha del inventario de que se tratara. Su elaboración era motivo de una concienzuda preparación, ya que cualquier error o manipulación en el importe del inventario tenía un efecto decisivo sobre el cálculo de la utilidad de la empresa.

Estos libros tenían una relación directa con el de balance, porque éste expresaba la situación financiera de la empresa en un momento determinado. Era un documento que recibía el nombre de balance de comprobación, denominación siempre seguida de la expresión de la

${ }^{12}$ En resumen, la duplicación del trabajo que representaban los pases al mayor, así como la demora que ocasionaban los pases mensuales en un diario tabular, hicieron pensar que estos libros se eliminaran, sin prescindir por ello de la calidad técnica del diario como informe cronológico de operaciones, ni de la del mayor como informe estadístico de esas mismas operaciones. La solución a este problema fue la llamada "contabilidad por copia" o de "registro simultáneo", que consistía en asentar las operaciones simultáneamente en el diario y en el mayor. 


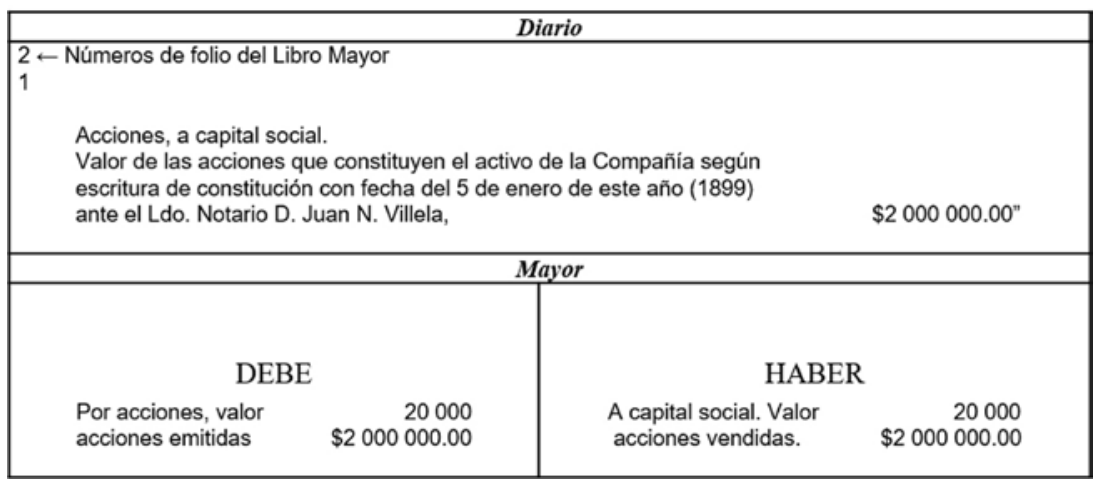

Guadro 1. Muestra de cuentas del libro diario y del libro mayor. AHEm, serie contabilidad, libro diario, exp. 001 y libro mayor, 1899, exp. 036.

fecha a que dicho documento se refería. Por una parte se anotaba el conjunto de cuentas - ya fuesen de pasivo o del activo-, y por la otra, en la misma hoja, se mencionaban las personas o instituciones involucradas en unas u otras. El Cuadro 2 muestra un ejemplo de balance, en el que la CiASA resulta ser deudora en el rubro de "cuentas".

En los libros de balance tenemos el estado que manifiesta la formación del activo y el pasivo, y como resultado el capital líquido o capital contable que poseía la empresa. Ahí se especificaban las ganancias del año transcurrido, y el reparto o los usos que se darían a las mismas: cuánto se reinvertiría, cuánto se guardaría como reserva y cuánto se pagaría como dividendo a los accionistas. Estos libros servían esencialmente para comprobar que los asientos registrados en el diario habían pasado íntegra y correctamente al mayor; también servían para calcular los saldos de las cuentas.

El balance era un documento que expresaba una determinada situación, donde por una parte se enlistaban los deudores del negocio, y por la otra los acreedores, doble lista que se refería a una fecha precisa. El balance de comprobación no era más que una lista de las cuentas del mayor que, en última instancia, solo comprobaba que los cargos habían correspondido a los abonos en todas y cada una de las operaciones registradas. De esta manera, el balance no solo satisfacía 
los fines de verificación arriba mencionados, sino que permitía hacer un estudio crítico de las cuentas.

Encontramos, pues, que el balance de comprobación contenía todas las cuentas, ya fuesen de activo, pasivo o de resultados, pero, sin clasificación alguna. A diferencia, el inventario contenía exclusivamente las cuentas del activo, pasivo y de capital, así como las de pérdidas y ganancias, todas debidamente clasificadas y ordenadas. La información que proporcionaba el balance no solo era útil para saber cómo la empresa llevaba sus operaciones, sino también para conocer el curso de sus mismas actividades, ya que los balances se hacían por lo menos una vez al año.

En el archivo de la CiASA existe también otro libro, el borrador, que era de gran utilidad, principalmente para el tenedor de libros y/o el contador. En él se asentaban diariamente y por orden de fechas, todas las operaciones que se verificaban en las transacciones; esto se hacía con el mismo orden que en el libro diario, pero con la diferencia de que en el borrador, como su nombre lo indica, se podían corregir los errores, borrando o raspando, en caso de ser necesario, los errores que hubiese, para pasar después los asientos al diario con toda exactitud y limpieza. La empresa, o el encargado, llevaban este libro de la manera que le convenía, según lo permitía el artículo 36 del Código de Comercio. ${ }^{13}$

Otro de los libros auxiliares fue el de compras; ahí se asentaba un resumen sucinto de las facturas recibidas de los proveedores. Hay que añadir el libro de ventas, que se llevaba del mismo modo que el anterior, solo que con las facturas emitidas. También se tenía el libro de cuentas por cobrar, que se llevaba a dos páginas, en donde se anotaban las entradas y salidas de letras y remesas con el detalle de las facturas. Otro de los auxiliares era el de cuentas varias, destinado a las operaciones que no entraba en ninguno de los libros anteriores.

${ }^{13}$ Del Raso, Curso completo, p. 37. 


\begin{tabular}{|c|c|c|c|c|c|}
\hline \multicolumn{6}{|c|}{ Balance de Comprobación del mes de enero de 1904.} \\
\hline Folio & Cuentas & DEBE & HABER & Deudores & Acreedores \\
\hline 1 & Capital Social & & $3500,000,00$ & & $3500,000.00$ \\
\hline 2 & Muebles Maquinaria-Electricidad & 2180.781 .84 & & & \\
\hline 3 & Predios Rústicos & $371,443.50$ & 335.288 .53 & $36,156,97$ & \\
\hline 4 & Inmuebles-Obras Hidráulicas & $2095,858.25$ & & $2095,858.25$ & \\
\hline 5 & Muebles y útiles & $3500,000.00$ & & $3500,000.00$ & \\
\hline 6 & F. C. de Xico a San Rafael & $172,175,64$ & & $172,175.64$ & \\
\hline 7 & Empréstito & & 1400.000 .00 & & 1400.000 .00 \\
\hline 8 & Ganancias y Pérdidas & & $334,703.11$ & & $334,703.11$ \\
\hline 8 & Fondo de Reserva & & 5683.54 & & 5683.54 \\
\hline 10 & Fondo de Previsión & & $51,153.10$ & & $51,153.10$ \\
\hline 11 & Deposito & 5275.00 & & 5275.00 & \\
\hline 12 & Accionistas & 2773.75 & & 2773.75 & \\
\hline 13 & Seguros contra incendios & 12229.19 & & 12229.19 & \\
\hline 14 & Timbres de $5 \%$ & 5200.85 & 8903.70 & & 3762.85 \\
\hline 15 & Documentos a Pagar & & $853,168.81$ & & 853.168 .81 \\
\hline 16 & Interesas y Descuentos & 1880.91 & 110.35 & 1750.56 & \\
\hline 17 & Cambios & 5847.46 & 68523.34 & & 62675.88 \\
\hline 18 & Banco Nacional de México & 13853.86 & 13853.86 & 7.86 & \\
\hline 19 & Banco de Londres y México & 93932.08 & 83085.89 & 8868.39 & \\
\hline 20 & Banco Central & 159.85 & 159.85 & & \\
\hline 21 & Caja & $218,572.71$ & 203729.31 & 13843.50 & \\
\hline 22 & Comisión en Puebla & 34848.29 & 38914.74 & & 4086.45 \\
\hline 23 & Fondos en Metepec & 51805.47 & 52072.53 & & 267.08 \\
\hline 25 & Explotación Ferrocarril & 846.10 & 786.00 & 80.10 & \\
\hline 26 & Explotación Pueblo & 133.00 & 1817.00 & & 1484.00 \\
\hline 28 & Refacciones & 36698.81 & & 36698.81 & \\
\hline 30 & Manufacturas & 752785.76 & 187.55 & 172598.21 & \\
\hline 34 & Mercancias & 693247.61 & 187174.04 & 506073.57 & \\
\hline 38 & Gastos Generales & 2403.76 & 341.00 & 2062.76 & \\
\hline 43 & Cia. del Ferrocarril de Xico & 17548.73 & & 17548.73 & \\
\hline 44 & John M. Summer \& Cia. & & 36543.93 & & 36543.93 \\
\hline 45 & A. Ricahud \& Cia. & 5000 & 7897.66 & & 2897.93 \\
\hline 46 & Mother \& Platt Ltd. & & 2825.91 & & 2825.81 \\
\hline 47 & Jonson \& Bariow Сis. & & 2214.82 & & 2214.82 \\
\hline 48 & Edward Word \& Cia. & & 24347 & & 24347 \\
\hline 49 & A. Kellog \& Dorian Sud. & & 330.85 & & 330.85 \\
\hline 50 & Escher Wyes Co. & 4000.00 & & 4000.00 & \\
\hline 51 & Kart Joket & 105.00 & & 105.00 & \\
\hline 52 & Iñigo Noriegs & 2215.00 & & 2215.00 & \\
\hline 53 & Fernández Somellora y Cia & 30129.43 & 363.917 .31 & & 333787.88 \\
\hline 55 & Luisa de Teresa Vda. De Peláez & & 109725.00 & & 109725.00 \\
\hline 56 & Suc. de José Zorrilla y Cia. & 18375.08 & 106459.00 & & 88083.92 \\
\hline 57 & Jacoby \& Cia & & 5959.72 & & 5959.72 \\
\hline 58 & Feliciano Cobian y Hnos. & 82.55 & 7437.24 & & 7354.69 \\
\hline 59 & Buenaventura Fernández & 7253.44 & 250.00 & 7003.44 & \\
\hline 60 & Benigno Diez Salcedo & 5495.09 & 6322.57 & & 827.48 \\
\hline 61 & Adolfo Weinzorn & 201.27 & 2521.16 & & 2319.88 \\
\hline 62 & Francisco Gálvez & 982.31 & & 982.31 & \\
\hline$\overline{83}$ & Alejandro Diez Salcedo & & 1162.41 & & 1162.41 \\
\hline 64 & José García Berinal & 480.00 & & 480.00 & \\
\hline 85 & Julio Soto & 87.00 & 200.00 & & 113.00 \\
\hline 52 & Cuentas Corrientes & $1063,544.40$ & 127991.63 & 935552.77 & \\
\hline & & $7919,490.30$ & $7919,490.30$ & $6810,354.96$ & $6810,354.96$ \\
\hline
\end{tabular}

Guadro 2. Balance de comprobación. AHEM, serie contabilidad, libro de balance de comprobación, 1904, exp. 125. 
Por medio de estos libros el tenedor de libros pasaba los asientos al diario y posteriormente al mayor. Finalmente, en el libro de caja - que también era un libro auxiliar - se registraba todo movimiento de entrada y salida de dinero en efectivo: en el "debe" se anotaban las entradas de dinero y en el "haber" las salidas, asentando los motivos de tales movimientos. Prácticamente se apuntaba bajo el mismo sistema que en el libro mayor; se trataba de un libro útil para conocer los gastos que la empresa realizaba cada día, semana o mes. ${ }^{14}$

La correspondencia relacionada con los asuntos contables fue fundamental para el trabajo contable de la CIASA; era considerada como documentos de base, porque en toda carta emitida existían dos partes: la parte contrato, formada por frases cortas, claras y concretas, que indicaban los términos de la operación entablada; y la parte explicativa, persuasiva o "psicológica", que variaba con cada destinatario. El redactor de ese tipo de correspondencia debía conocer a fondo la variedad, características y precio de los artículos que producía la empresa o los insumos que requería; también debía conocer a la clientela y a los proveedores, y nunca debía dejar una carta sin contestar. Toda esa correspondencia formaba los libros copiadores de cartas, en los cuales se copiaba cada carta, oficio, memorándum o telegrama, relacionados con las transacciones de la empresa.

Otros documentos que están relacionados con la parte cuantitativa, pero a su vez nos proporcionan información cualitativa son,

${ }^{14}$ Había también otros documentos, no menos importantes, que complementaban la contabilidad de la ciasa: los llamados libros de orden, como el de Almacén, que servía para inscribir las mercancías que entraban y salían como resultado de las operaciones al por mayor que se realizaban. En éstos se consignaban todos los gastos que tenía la empresa por concepto de materias primas, los proveedores de los cuales las obtenían, así como las ventas que realizaba y con quién las realizaba. Estos libros tenían una estrecha relación con los de ventas y los de deudores diversos, ya que en éstos se anotaban las ventas al menudeo y al mayoreo, y en aquéllos las cuentas que llevaba la empresa con sus principales clientes. Además, y como es fácil deducir, de todas estas operaciones emanaban largas series de facturas - tanto emitidas como recibidas-, las cuales también se encuentran en el archivo. 
por ejemplo, los libros de la empresa R.G. Dun, con información personal de los accionistas, acreedores o deudores o los libros de rayas, donde se anotaban los folios semanales con los nombres de los obreros y obreras por departamento (de hilados, tejidos, repaso y atado, talleres, urdidores, crudo y color, estampe y acabado, engomado y cañoneros), el salario percibido por cada uno en la correspondiente semana, y las deducciones que se hubiesen efectuado. En éstos se puede hallar información sobre aspectos no solo contables sino sociales, como por ejemplo la movilidad laboral. También se hallan diversas listas de operarios, de empleados extranjeros, de los jubilados y hasta de los maestros de escuelas.

Reflexionar sobre el funcionamiento interno de la CIASA a través de su documentación, bien puede considerarse como una labor de "arqueología documental"; una tarea que se ha emprendido tratando de recuperar y de respetar el sentido original y lógico que tuvieron

\begin{tabular}{|c|c|c|c|}
\hline Principales & Auxiliares & Básicos & Orden \\
\hline Libro Mayor & Caja & & \\
Libro Diario & Compras & $\begin{array}{c}\text { Correspondencia emitida } \\
\text { (sobre cuentas) }\end{array}$ & Almacén \\
Inventarios & Ventas & & \\
Balance y comprobación & Cuentas por cobrar & & \\
& Cuentas varias & & \\
& & & \\
& & & \\
\hline
\end{tabular}

Guadro 3. Los libros de contabilidad que usaba la ciasa estaban divididos en principales, auxiliares, básicos y de orden. El Archivo Histórico del Museo Industrial de Metepec cuenta con las series completes de éstos, de 1898 a 1967.

los documentos que lo forman, para así reconstruir series, establecer dinámicas, conocer su evolución de la forma lo más veraz posible. Una fuente como ésta es una sólida plataforma para elaborar historias con bases que, por supuesto, son insuficientes si no se acompañan de los datos de otras fuentes y de los análisis necesarios, frente a las cuales debemos tener una sana crítica marcando una distancia. Pero aun así son de las bases más concretas y firmes con que un investigador puede contar. 


\section{La organización del fondo GIASA}

Los archivos no surgen de la nada, no nacen de un acto espontáneo de uno o varios individuos, sino que son producto de un contexto determinado, de una serie de actos que se van ligando entre sí para dar sentido a una acción o a un fenómeno social, que a su vez es parte de otro contexto más amplio y que produce acciones mayores e incluso procesos decisivos para la sociedad. Son un producto que nace de una "acción administrativa", dice Jorge Nacif, y con la función específica de servir de testimonio. Sus documentos se expiden o se reciben en una institución o dependencia y reflejan las acciones y los objetivos propios de la misma. Se conservan como prueba y continuidad de una gestión administrativa. ${ }^{15}$ Es decir, el documento es un testimonio material capaz de referir un hecho, aun cuando carezca de formas legales.

Los archivistas holandeses Muller, Feit y Fruin, coinciden en que el archivo es "el conjunto de documentos - escritos a mano, dibujados o impresos - recibidos o redactados ex oficio por la autoridad o por un empleado de ésta, mientras que tales documentos, conforme con su función, tengan que parecer junto a la misma autoridad o junto a sus empleados". ${ }^{16}$ En esta definición se utiliza el término conjunto que posteriormente retomarían otros estudiosos del asunto, como la española Antonia Heredia que dice: "El conjunto [de documentos] no es el resultado de un acto voluntario o caprichoso de alguien" "...el conjunto de documentos es recibido o despachado por una persona o una institución pública o privada que resulta de su actividad, organizados de acuerdo con ésta y conservados para su utilización". ${ }^{17}$ Por otro lado, el norteamericano Theodore R. Schellenberg señala que los archivos "merecen ser permanentemente conservados con fines de referencia o de investigación, y que han sido depositados o seleccionados para ser guardados en una institución archivística”. ${ }^{18}$

\footnotetext{
${ }_{15}$ Nacif, La Valoración, p. 21.

${ }^{16}$ Lodolini, Archivística, p. 136.

${ }^{17}$ Heredia, Archivistica general, p. 62.

${ }^{18}$ Schelemberg, Archivos modernos, p. 42.
} 
Podemos decir entonces, que el archivo forma una conjunción de elementos que se ubican como piezas integrantes de un todo; de un "cuerpo", cuyas partes desarrollan funciones específicas que dan, a fin de cuentas, la idea de organicidad. En ese cuerpo confluyen la materia y la organización documental que se refieren a su forma. La finalidad inmediata del archivo, que representa el servicio, las relaciones entre los documentos y su sucesión en el tiempo, así como las diversas formas de estructuración que el archivo va tomando a lo largo de su existencia. ${ }^{19}$

En este sentido, debemos entender al archivo no como un objeto aislado, sino en sus relaciones y sus aparentemente distintas formaciones documentales o cuerpos. Además, hay que mirarlo como una serie de construcciones que, si bien tienen sus propias particularidades, de alguna manera se enlazan entre sí para dar un sentido total en procesos de estructuración documental. Entender, pues, que cada una de las partes integrantes de un archivo pueden estar relacionadas con las de otro archivo, y a su vez éste como parte de otro proceso más amplio de formación e integración documental. Por ejemplo, entre Aнмiм, el Archivo Histórico del Agua (AHA-Canagua), el Archivo General de la Nación (AGN) y el Archivo Histórico Municipal de Atlixco (AHMA), existe una relación a través de gran cantidad de documentos sobre la CIASA.

Hay que considerar pues, al archivo, como una constante interrelación consigo mismo y entre sus diversos elementos constitutivos, con otros archivos como parte de una totalidad sin límite desde sus propias condiciones y características y, finalmente, con el contexto, no necesariamente con el documental o discursivo, sino más bien con el institucional y sus prácticas políticas, económicas y sociales, las que le dan sentido y esencia. ${ }^{20}$

Asimismo, no hay que dejar de lado la datación de sus documentos y su desarrollo a lo largo del tiempo. Es necesario saber en qué momento comenzaron y terminaron sus funciones, cuándo se

${ }^{19}$ Villanueva Bazán, El archivo, p. 2; De la Torre Villar, La investigación bibliográfica, p. 134.

${ }^{20}$ Villanueva Bazán, El archivo, p. 9. 
convirtió en archivo de concentración y el momento cuando se inició como archivo histórico. ${ }^{21}$ Momento en el que debemos pensar en el archivo como un proceso de formación "natural" de documentos, cuyos límites, formas y discursos, están delineados y dispuestos de cierto modo, a partir de la existencia misma de las instituciones que los generaron, de la forma en que éstas se estructuran y plantean sus relaciones internas y su vinculación con entidades externas. ${ }^{22}$

Podríamos decir entonces, que el archivo histórico de la ciasA tiene su comienzo en el momento en que se produjo el primer documento; una continuación mientras siguieron utilizándose los documentos que fue acumulando la empresa, y un término de su vigencia administrativa, cuando ésta fue liquidada. Schellemberg nos habla de los "valores primarios" de un archivo, cuando está en funciones, y de los "valores secundarios" cuando termina su actividad original y pasa, si es reutilizado, a un nuevo nivel de significación. ${ }^{23}$ Es en el momento en que el archivo pierde su vigencia administrativa y se produce otro inicio abriéndose la puerta a un nuevo desarrollo como archivo histórico.

Desafortunadamente, existen archivos de empresa que al perder vigencia administrativa y convertirse en archivos históricos, han sido "reestructurados" y "reorganizados" de manera errónea, a veces por archivistas o historiadores que, para satisfacer una demanda

${ }^{21}$ Jacques Derrida distingue el concepto de inicio como la posibilidad de un origen, de un comienzo que implica en sí la posibilidad de un desarrollo, y que por tanto entraña un espacio de tiempo formado por una secuencia; es decir, una serie de momentos posteriores al origen, que dan sentido total al proceso de creación y acumulación documental. Esta idea va de la mano con el afán del historiador por hallar los orígenes de "algo" (un pasaje de la historia, un suceso o acontecimiento). Así pues, esa reflexión se extiende lógicamente al archivo, pues en éste se halla la principal "materia prima" con que trabaja el historiador, así como se hallan en sus documentos los datos e informaciones, o al menos las pistas de los comienzos, principios o inicios de ese "algo". Derrida, Mal de archivo, p. 3.

22 Derrida, Mal de archivo, p. 3.

${ }^{23}$ Schelemberg, Archivos modernos, p. 42. 
específica de información, no toman en cuenta que los documentos tienen un orden original que debe respetarse, como parte esencial del trabajo archivístico. Si se desvincula un documento de sus demás correspondientes, es probable que se estén formando series que poco o nada tienen que ver con el conjunto orgánico que forma el archivo de que se trate, con ese todo que ya estaba estructurado de manera sistemática, o al menos con cierta lógica.

En el caso particular del fondo ciasA, así como el método de organización documental de todo el AHMIM, está sustentado en el principio de procedencia y el respeto del orden original, pero también, para lograr su debida estructuración, conocer el contexto en el que se redactaron los textos o documentos ha sido indispensable. Para que esto se cumpliera, fue preciso conocer los antecedentes históricos de cada fondo y de las instituciones, su funcionamiento y su estructura. En el caso particular del fondo CIASA, la red administrativa que generó sus documentos, y las razones por las que fueron elaborados tales o cuales escritos o libros. Además, lo que se sabe de la historia de los orígenes de cada fondo, es a partir de lo publicado por varios investigadores, lo que nos permitió tener una buena base para organizar, clasificar e inventariar los documentos.

No es de extrañarse que, como sucede en todas partes, así como en infinidad de ocasiones, una gran cantidad de documentos se han perdido a lo largo de la historia, algunos por el pasar del tiempo y otros más por falta de conciencia del hombre, quien ha permitido e incluso hasta ha promovido su destrucción. En el caso del fondo CIASA no podía ser una excepción, pero afortunadamente las mermas parecen ser realmente mínimas. En él se conserva casi toda la documentación producida por la empresa durante 68 años: documentos de distinto tipo, de distinta data y de distinta importancia, que hablan principalmente de su historia industrial, laboral y económica, desde su fundación hasta su desaparición.

El acervo cuenta con secciones y serie de expedientes que nos hablan de diferentes periodos históricos de la empresa, desde la construcción de la fábrica y su caserío obrero, de la Revolución mexicana 
y su injerencia en la fábrica, de la organización de los obreros y las huelgas, hasta 1964, cuando a la CIASA ya no le interesa revisar el contrato colectivo y decide dejar a la organización sindical la fábrica y el caserío. Momento en que la agrupación obrera forma una cooperativa, pero no logra mantenerse en pie, por lo que tiene que cerrar definitivamente en 1967.

Es importante mencionar que el acervo se encontró en total desorden y algunos materiales estaban en mal estado. Luego de su recuperación hubo un intento de organizarlo, pero quienes pretendieron hacerlo solo mezclaron los documentos y no dejaron un solo registro de lo supuestamente organizado. A partir de 2002 se comenzó desde

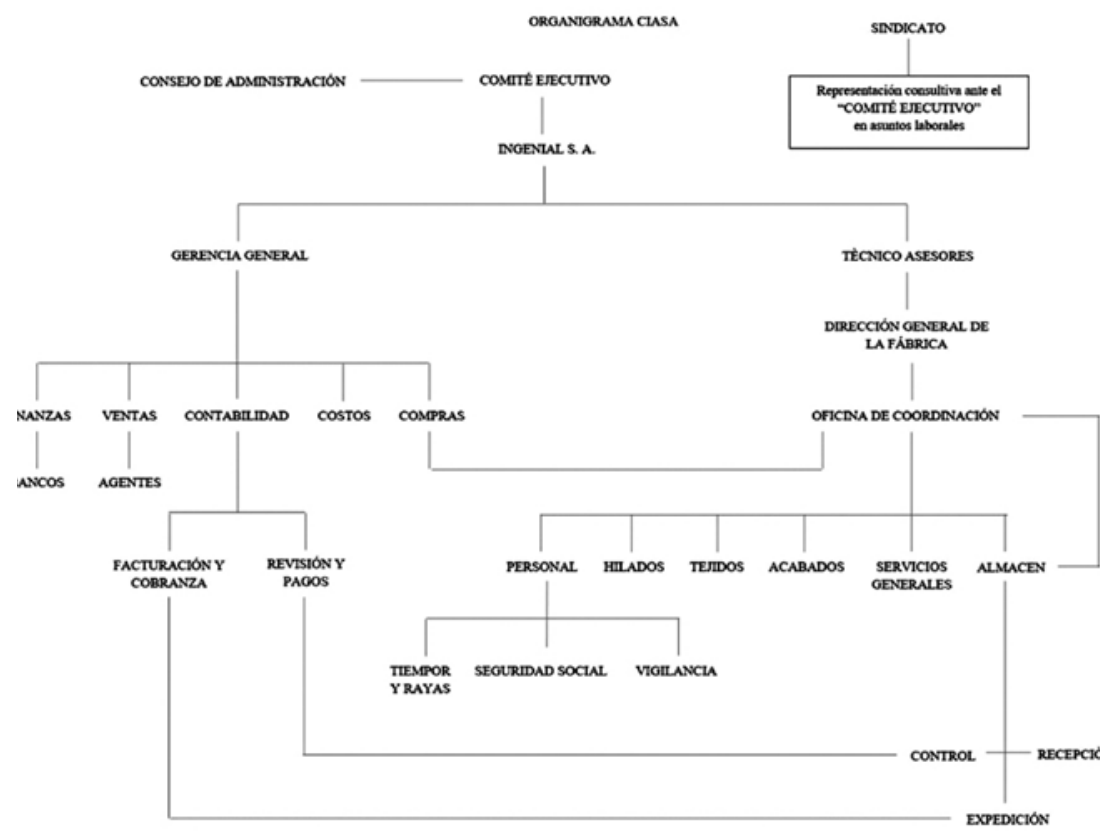

Imagen 4. El organigrama corresponde a los últimos años de la fábrica. Ingenial S. A., era una empresa que se cree asesoraba a la cooperativa de obreros entre 1964 y 1967. Archivo Histórico del Museo Industrial de Metepec, serie estatutos, exp. 005, s/f. 
"cero" el trabajo de ordenación: desde la separación de los documentos en mal estado, hasta la limpieza, colocación y organización de cada uno de los documentos. Posteriormente, en diciembre de 2004, con el aporte financiero de una asociación civil denominada Apoyo al Desarrollo de Archivos y Bibliotecas de México (ADABI), se terminó el último proceso del proyecto de "Rescate y organización e investigación del archivo de la CIASA", quedando listo para ser consultado.

Un organigrama hallado entre la masa de papeles fue fundamental para la organización del mismo, pues nos sirvió de guía para iniciar la estructuración. Dicho documento nos dejó ver que la empresa estaba fundamentalmente dividida en tres órganos básicos, siendo el primero: el consejo de administración, seguido por el comité ejecutivo, que creemos estaba constituido por del sindicato, por la época que correspondía ese organigrama. ${ }^{24} \mathrm{El}$ segundo, emanado del anterior, lo formaban dos secciones: la gerencia general, que controlaba lo administrativo, y la otra sección, integrada por los asesores técnicos, la dirección general de la fábrica y la oficina de coordinación, que en ese orden de importancia organizaban todo lo relacionado con la producción y sus aspectos técnicos. Finalmente, existía un tercer órgano derivado del segundo, formado por los departamentos que conectaban lo administrativo y lo técnico a través de diferentes oficinas.

Gracias a ese organigrama se pudo realizar el trabajo intelectual de ordenación archivística y posteriormente el inventario. La organización actual del archivo está, entonces, formada por una

${ }^{24}$ Este organigrama no tiene fecha, pero se presume que corresponde a los últimos años de actividad de la fábrica, cuando ésta pasó a ser administrada por el sindicato de trabajadores, de 1964 a 1967. Para nosotros fue una herramienta insustituible, porque nos permitió, por una parte, conocer la estructura orgánica de la empresa, y de alguna manera también la historia del archivo; por otra parte, sirvió para respetar el principio de procedencia de la documentación. Este documento fue la base para la organización del archivo de la CIASA. De su estructura se utilizaron, principalmente, tres órganos, (el Consejo de administración, la Gerencia general, y la Dirección general de la fábrica), completándose con la conformación archivística de lo que decidimos denominar Departamento jurídico, lo mismo que de algunas series. 
gran sección, que es el consejo de administración, con sus series de expedientes; asimismo, esta sección se divide en tres subsecciones, la gerencia general, la dirección general de la fábrica y el departamento jurídico que, del mismo modo, se encuentran subdivididas en sus respectivas series de expedientes.

Fue necesario priorizar el inventario como forma descriptiva más acorde con las necesidades y la esencia del archivo CIASA. El inventario, al describir las series, otorga a la documentación ese contexto necesario para la cabal comprensión de todos los elementos que integran el archivo, entendiéndolo como conjunto, como agrupación orgánica y no solamente como un agregado de documentos sin relación entre sí. El inventario es, pues, el contexto. Resume la historia de la empresa que ha producido el archivo e indica las competencias, las estructuras, el modo del funcionamiento, la evolución de la institución y el modo según el cual el material está ordenado.

La mayor parte de los documentos encontrados en el archivo de la CiASA son de tipo contable, aunque también existen documentos que nos proporcionan datos e informaciones no cuantitativas. Los documentos básicos para poder conocer la historia de una empresa son los libros de actas de asambleas generales de accionistas y de actas del consejo de administración. En las primeras se asentaban los acuerdos de las reuniones generales de accionistas y en las segundas se resumían las discusiones habidas en las reuniones de los miembros del consejo y se asentaban también los acuerdos tomados. Cabe destacar que las actas de asambleas generales de accionistas están completas y van de 1899 a 1967. En los libros que las contienen hallamos, por ejemplo, el acta de constitución de la empresa y sus estatutos, así como los resúmenes de los balances generales y los votos para la elección de los miembros del consejo, entre otras muchas cosas.

Además, dentro del rango de documentos no contables se hallan valiosos documentos, como por ejemplo, el apreciado film de 1923, en formato de $16 \mathrm{~mm}$, único en toda Latinoamérica, que en aproximadamente una hora muestra todo el proceso productivo de la fábrica de Metepec, desde la llegada del algodón hasta la salida de los obreros al terminar 
la jornada. ${ }^{25}$ Otro ejemplo es la serie reclamaciones, fuente única donde podemos encontrar lo referente a las incursiones y saqueos por parte de las fuerzas revolucionarias en la fábrica de Metepec, de 1911 a 1917. En este expediente se hallan desde cartas, oficios, comunicados, certificados notariales y hasta los inventarios de los deterioros y las pérdidas de telas, herramientas, armas y dinero en efectivo.

Otro ejemplo de la singularidad y riqueza del fondo CIASA, es la serie de expedientes marcas de fábrica. Ahí se localizan expedientes del registro de patentes con las etiquetas con que eran identificadas la producción de diferentes telas, entre 1903 a 1912, con imágenes como el escudo nacional, la flora y fauna de la región, la panorámica de la fábrica y los volcanes o alegorías de la mitología griega. Posteriormente, se produjeron etiquetas muy sencillas, que sólo contenían el nombre del producto sin ninguna imagen, como por ejemplo "Tela de Metepec 32".

También encontramos series con los expedientes de las propiedades de la empresa como son las series fincas urbanas y fincas rústicas. Ahí se consignan todos los bienes raíces con los que contaba la empresa, amparados por sus respectivas escrituras, como las oficinas centrales de la compañía en la Ciudad de México, o los bienes en el estado y ciudad de Puebla. Asimismo se halla la serie de obras hidráulicas, con sus documentos sobre las concesiones de tierra para construir los canales para transportar, almacenar y distribuir el agua. También se hallan las importantes series de ferrocarriles o concesiones, entre otras relacionadas.

Una de las series que no puede dejar de mencionarse y que también proporciona datos más que nada cualitativos, es la de correspondencia recibida, donde se hallan unas cien mil cartas que

${ }^{25}$ Un filme en $35 \mathrm{~mm}$ se encontró entre el montón de documentos de la CIASA, antes de haber sido llevado a la ex fábrica y de crear el Archivo Histórico. La cinta se hallaba en muy mal estado de conservación, así que el maestro Samuel Malpica, la llevó a la Filmoteca de la Universidad Nacional Autónoma de México, donde fue restaurado y titulado "México industrial" y hasta la fecha lo tiene bajo su resguardo. Se tiene registro que en 1996 la filmoteca hizo una copia en $16 \mathrm{~mm}$ y que es la que tiene el Archivo Histórico del Museo Industrial de Metepec (AHMIM). 
los comerciantes y otras personas dirigían a la empresa, relacionadas con transacciones y otros asuntos. Por ejemplo, ahí existe la correspondencia con el gobierno, con los sindicatos, con los socios y proveedores extranjeros, y con otras fábricas del ramo. Cabe decir que esta serie de expedientes está organizada en orden cronológico y alfabético. También se encuentra la serie de correspondencia emitida, pero ésta tiene que ver más con la contabilidad y por ello resumiremos su contenido más adelante.

A partir del organigrama, la investigación sobre la organización de los documentos y la organización el cuadro fue constituido de manera jerárquica por la primera sección: consejo de administración, con sus series de expedientes relacionados directamente con el consejo de accionistas. Esta misma sección se subdividió por tres subsecciones: gerencia general, dirección general de la fábrica y departamento jurídico, con sus series de expedientes. Cada una está constituida por documentos administrativos, técnicos y legales relacionados directamente con la fábrica de Metepec, respectivamente. Como se aprecia en el cuadro se describe de manera general la formación de los expedientes con sus fechas de inicio y terminación.

\section{Conclusión}

La recuperación, conservación y organización de los archivos de empresa, en general, y el archivo de la ciASA en particular, ha sido uno de los retos más importantes al que nos hemos enfrentamos en nuestra labor de investigación, puesta en valor y preservación del patrimonio cultural (industrial). Por esta razón subrayamos que si de verdad queremos preservar los registros originales de nuestro pasado industrial, no debemos dejar de pensar que los trabajadores son tan importantes, o más aún, como la máquinas y los edificios, y que los archivos de empresa son esencialmente un bien de la sociedad y de los personas que hicieron funcionar la industrial en nuestro país. 


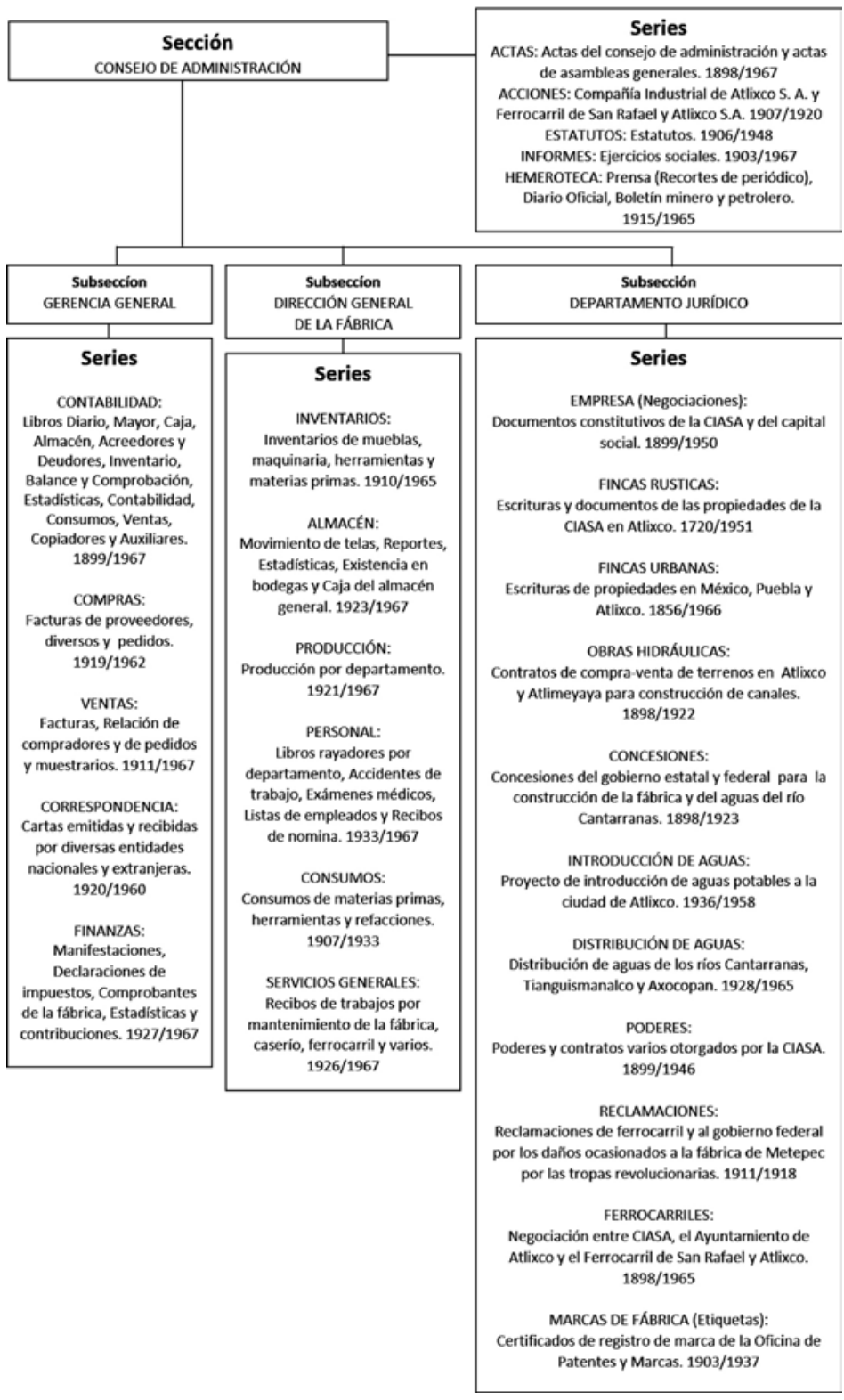

Guadro 4. Guadro de clasificación del fondo documental CiAsA.

Fuente: elaboración propia. 
Conservar los documentos históricos, y en este caso los de empresa, significa dar la oportunidad de conocer su pasado a quienes lo han heredado, esto es, al grupo social que encontrará en ellos su identidad. En este sentido, la defensa del patrimonio documental debe ser considerada como un sistema en el que deben interactuar las partes esenciales que lo integran: los propietarios de las empresas, las autoridades gubernamentales, las instituciones encargadas de su preservación, los profesionales responsables de su ordenación y difusión, y la sociedad misma.

Reflexionar sobre estos archivos es fundamental, ya que son pocos los repositorios que los contienen. No existe una conciencia preservacionista por parte del empresariado y, por tanto, no son considerados como bienes históricos comunes. Es importante que los acervos documentales de empresa sean reconocidos como parte del patrimonio y fuente para la investigación, lo que permitirá realizar acciones para su defensa, rescate y conservación. Sin embargo, es responsabilidad tanto de aquellos que tienen a su cargo los bienes documentales, los tomadores de decisiones, los académicos y la sociedad, porque somos todos los representados en los procesos de conservación de nuestro pasado.

Finalmente, es importante aclarar que estos acervos son elementos imprescindibles para recuperar la memoria de un grupo social. Por eso, la transmisión de la memoria colectiva de una generación a otra depende en gran medida de la continuidad de esas huellas materiales del pasado, de esos "monumentos de papel" de nuestra época, que son sin duda patrimonio cultural y, su preservación, la garantía de perdurabilidad. 


\section{Fuentes}

\section{Bibliografía}

Castañeda G., Ma. del Rocío, "Las vertientes de los ríos: modernización y conflicto social en Atlixco, Puebla, 1880-1920", tesis de doctorado inédita en Historia, México, El Colegio de México, 2001.

Castellanos Arenas, Mariano, "Legislar para conservar", en Noelle (Ed.), El patrimonio de los siglos XX y XXI, 15o. Coloquio del Seminario de Estudio y Conservación del Patrimonio Cultural, México, Universidad Nacional Autónoma de México, 2011, pp. 162-167.

Código de Comercio de los Estados Unidos Mexicanos, México, Librería de la Vda. de Ch. Bouret, 1913.

De La Torre Villar, Ernesto, La investigación bibliográfica, archivistica y documental, México, Universidad Nacional Autónoma de México, 2003.

Del Raso, Bernardo, Curso completo teórico práctico de teneduría de libros por partida doble, Imprenta de "El gran libro", España, Parrés y Cía. Sucs., 1890.

Derrida, Jacques, Mal de archivo. Una impresión freudiana, (Trad. Paco Vidarte), España, Editorial Trotta, 2004.

Foucault, Michel, La arqueología del saber, México, Siglo xxi Editores, 1982.

Gamboa, Leticia, Los empresarios de ayer. El grupo dominante en la industria textil de Puebla, 1906-1929, Puebla, Benemérita Universidad Autónoma de Puebla, 1985. 
Gavilán, César Martín, Fondos documentales: identificación, descripción, valoración y selección, E-LIS. E-prints in Library and Information Science, USA, 2009.

Heredia, Antonia, Archivística general. Teoría y práctica, España, Diputación Provisional de Sevilla, 1987.

"International Committee for the Conservation of the Industrial Heritage, TICCIH, Congress, 1973", Published by the lronbridge Gorge Museum Trust, Church Hill, Ironbridge, Telford, Shropshire, England, 1975; http://works.bepress.com/theinternationalcommitteefortheconservationoftheindustrialheritage/11/

Islas, María Estela, "Los archivos, acercamiento teórico", en Archivística, vol. v (número especial), México, Instituto Politécnico Nacional, 2003.

Lodolini, Elio, Archivistica, principios y problemas, España, Asociación Española de Archiveros, Bibliotecarios y Documentalistas (ANABAD), Colección Manuales, 1993.

Malpica, Samuel, Arqueología Industrial de Metepec, CD Rom, México, Benemérita Universidad Autónoma de Puebla, 2002.

Metepec, la máquina urbana, México, Benemérita Universidad Autónoma de Puebla, 2002.

Nacif, Jorge, La valoración de los archivos, México, Archivo General de la Nación, 2002.

Pacheco, Pilar, "Los empresarios de la Compañía Industrial de Atlixco, S. A.”, tesis de licenciatura inédita en Historia, México, Benemérita Universidad Autónoma de Puebla, 1984. 
Prieto, Alejandro, Principios de contabilidad, México, Editorial Banca y Comercio, 1932.

Schelemberg, Theodore R., Archivos modernos. Principios y técnicas, La Habana, Instituto Panamericano de Geografia e Historia, 1958.

Villanueva Bazán, Gustavo, "El archivo: proceso de construcción documental", México, Ponencia Renaies, 2004. 